\title{
BMJ Open Use of a geographic information system to identify differences in automated external defibrillator installation in urban areas with similar incidence of public out-of-hospital cardiac arrest: a retrospective registry-based study
}

David Fredman, ${ }^{1}$ Jan Haas, ${ }^{2}$ Yifang Ban, ${ }^{2}$ Martin Jonsson, ${ }^{1}$ Leif Svensson, ${ }^{1}$ Therese Djarv, ${ }^{3}$ Jacob Hollenberg, ${ }^{1}$ Per Nordberg, ${ }^{1}$ Mattias Ringh, ${ }^{1}$ Andreas Claesson ${ }^{1}$

To cite: Fredman D, Haas J, Ban Y, et al. Use of a geographic information system to identify differences in automated external defibrillator installation in urban areas with similar incidence of public outof-hospital cardiac arrest: a retrospective registrybased study. BMJ Open 2017;7:e014801. doi:10.1136/ bmjopen-2016-014801

- Prepublication history and additional material are available. To view these files please visit the journal online (http://dx.doi.org/ 10.1136/ bmjopen-2016-014801).

Received 24 October 2016 Revised 10 March 2017 Accepted 20 March 2017

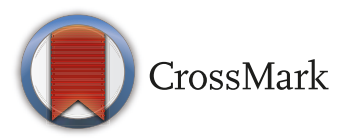

${ }^{1}$ Department of Medicine, Karolinska Institutet, Center for Resuscitation Science, Solna, Sweden

${ }^{2}$ Division of Geoinformatics, Kungliga Tekniska Hogskolan (KTH), Stockholm, Sweden ${ }^{3}$ Department of Medicine, Karolinska Institutet, Function of Emergency Medicine, Karolinska University Hospital, Stockholm, Sweden

Correspondence to David Fredman; david.a.fredman@ki.se

\section{ABSTRACT}

Objectives Early defibrillation in out-of-hospital cardiac arrest $(\mathrm{OHCA})$ is of importance to improve survival. In many countries the number of automated external defibrillators (AEDs) is increasing, but the use is low. Guidelines suggest that AEDs should be installed in densely populated areas and in locations with many visitors. Attempts have been made to identify optimal AED locations based on the incidence of OHCA using geographical information systems (GIS), but often on small datasets and the studies are seldom reproduced. The aim of this paper is to investigate if the distribution of public AEDs follows the incident locations of public OHCAs in urban areas of Stockholm County, Sweden.

Method OHCA data were obtained from the Swedish Register for Cardiopulmonary Resuscitation and AED data were obtained from the Swedish AED Register. Urban areas in Stockholm County were objectively classified according to the pan-European digital mapping tool, Urban Atlas (UA). Furthermore, we reclassified and divided the UA land cover data into three classes (residential, non-residential and other areas). GIS software was used to spatially join and relate public AED and OHCA data and perform computations on relations and distance.

Results Between 1 January 2012 and 31 December 2014 a total of 804 OHCAs occurred in public locations in Stockholm County and by December 2013 there were 1828 AEDs available. The incidence of public OHCAs was similar in residential (47.3\%) and non-residential areas $(43.4 \%)$. Fewer AEDs were present in residential areas than in non-residential areas $(29.4 \%$ vs $68.8 \%)$. In residential areas the median distance between OHCAs and AEDs was significantly greater than in nonresidential areas (288 m vs $188 \mathrm{~m}, \mathrm{p}<0.001)$. Conclusion The majority of public OHCAs occurred in areas classified in UA as 'residential areas' with limited AED accessibility. These areas need to be targeted for $A E D$ installation and international guidelines need to

\section{Strengths and limitations of this study}

- We have used rather simple GIS analyses available in most GIS software.

- The UA dataset of European land use and cover is freely available and therefore it is possible to reproduce our analyses.

- We do not identify high-risk areas for OHCAs or locations for AED installation but merely present the spatial relation of public AEDs and public OHCAs in Stockholm.

- The Swedish AED registry (SAEDREG) only holds information voluntarily reported by AED owners and lacks information on any AEDs sold but not registered in SAEDREG.

- Due to the data format for population density provided by Statistics Sweden, no analysis regarding demographics was performed in conjunction with the UA classifications.

take geographical location into account when suggesting locations for AED installation.

\section{INTRODUCTION}

Out-of-hospital cardiac arrest (OHCA) is a major public health problem in Europe, affecting some 300000 people each year ${ }^{1}$ with generally low survival rates of $5-10 \% .^{23}$ However, survival rates around $70 \%$ have been shown in cases where an automated external defibrillator (AED) is used by laypersons or trained non-medical responders within the first 3-5 min. ${ }^{45}$ During the last decade there has been an increase in the number of publicly available AEDs in many countries including Sweden, ${ }^{5-7}$ but the reported overall 
use of AEDs in OHCA is still relatively low ranging from $1.7 \%$ to $12.8 \% .^{589}$ Public AEDs are considered beneficial for OHCA in public locations, ${ }^{10}$ but AED installation in the homes of patients at risk for OHCA has not shown increased survival. ${ }^{11}$

Factors such as AED accessibility, bystander awareness and willingness to act and long distances from the location of OHCA to an AED may affect AED use. ${ }^{72-14}$ A distance of 100 metres between OHCA and AED is considered favourable for achieving defibrillation within the critical $3-5$ min after collapse. ${ }^{15} 16$ To facilitate early defibrillation, recent guidelines from the European Resuscitation Council (ERC) suggest that AEDs should be placed in densely populated areas and in locations with many visitors such as train and bus stations, airports, sport facilities, casinos and shopping malls. ${ }^{1}$ Efforts have been made to identify optimal locations for public AEDs by analysing OHCA incidence and/or AED locations using geographical information systems (GIS) ${ }^{16-19}$ These studies are often carried out on relatively small datasets in a single city or limited regions and they use diverse GIS methods, which may limit their reproducibility and generalisability.

The aim of this paper was to investigate if the distribution of public AEDs follows the incident locations of public OHCA in urban areas of Stockholm County, Sweden.

\section{METHODS \\ Study area}

Stockholm County contains the capital of Sweden and comprises 26 political municipalities. Covering $6526 \mathrm{~km}^{2}$ with 2231439 inhabitants $\left(342 / \mathrm{km}^{2}\right)$, Stockholm County is the most densely populated county of Sweden. However, including sparsely populated rural areas, over $70 \%$ of the population in Stockholm County are situated in areas classified as Urban core and Outer urban areas. ${ }^{20-22}$

In Stockholm County there is a two-tiered nurse-staffed ambulance system providing advanced life support in OHCA. In addition, a dual-or in some cases tripledispatch of fire department and police alongside the ambulance is used to shorten delay from call to arrival and enable earlier defibrillation. ${ }^{23} 24$

\section{Data collection}

Data were collected from the following sources.

Swedish Register for Cardiopulmonary Resuscitation (SRCR)

SRCR is a national population-based register including OHCA data since 1990 and all OHCA cases where the ambulance crew has initiated cardiopulmonary resuscitation (CPR) are reported to SRCR. ${ }^{25}$ OHCA cases are collected prospectively by the ambulance crew and case characteristics, bystander performance and interventions on-scene by the emergency medical service (EMS) is reported in accordance with the 2004 Utstein-style recommendations. ${ }^{25}{ }^{26}$ However, SRCR includes some more specific locations of OHCA such as train station, church and airport. ${ }^{25}{ }^{27}$ Since 2007, OHCA cases are reported in close connection to the corresponding emergency call through a web-based system and, from 2011, SRCR is estimated to include $100 \%$ of the OHCA cases in Sweden. ${ }^{25}$

\section{Swedish AED Register (SAEDREG)}

SAEDREG is a non-compulsory register of public AEDs in Sweden and contains information entered by AED owners on AED location (ie, address and coordinates) and accessibility (ie, access hours and owners' contact information). SAEDREG was established in 2009 and is managed by the Swedish CPR council. To ensure a high level of validity, an automated reminder is emailed every 6 months after registration and AED owners are asked to verify all entered data. Only owner-verified AED information is displayed on the SAEDREG web page. By December 2013, SAEDREG held information on 7078 AEDs. ${ }^{25}$ According to the Swedish Resuscitation Council, this accounts for $36 \%$ of the AEDs sold in Sweden based on figures from the AED companies in Sweden. ${ }^{25}$

\section{Urban Atlas digital mapping tool}

Urban Atlas (UA) is part of the European Commission's Global Monitoring of Environment and Security (GMES) land monitoring service. UA is pan-European and based on satellite images with a 2.5 metre resolution and provides digital high-resolution land cover maps of 299 larger urban zones in the European Union including all capital cities of member states. ${ }^{28} \mathrm{UA}$ data are supported by reference data such as topographic maps and contain 19 land use/land cover classes. ${ }^{28}$ UA data are freely available in the form of shape files from the European Environment Agency website. ${ }^{29}$ UA is primarily intended as inter-comparable and reliable urban planning data and is well-known and used for GIS analyses of urban areas in Europe. $^{30-32}$

\section{Selection of public OHCA cases}

From the SRCR, OHCA cases in which the EMS crew reported the location for collapse as being in public locations (ie, outside the home) were selected for the analysis. Cases reported as witnessed by the EMS crews were excluded.

\section{Selection of publicly available AEDs}

From SAEDREG, all publicly available AEDs in Stockholm County at 31 December 2013 were selected, regardless of location and opening hours of the AED venues.

\section{Obtaining geographical information}

The geographical locations of AEDs in Stockholm County were obtained from SAEDREG in the form of coordinate pairs in the RT90 coordinate system. ${ }^{33}$ The SRCR data did not contain addresses or coordinates of incidence locations of OHCA. The national dispatch organisation in Sweden stores the coordinates of all emergency calls in the incident logs. By matching the incident codes of the selected OHCA cases from SRCR with the incident logs from the dispatch centre in Stockholm County, the geographical coordinates were obtained in the form of coordinate pairs in the WGS84 coordinate system. ${ }^{34}$ 
To facilitate further GIS analysis and to preserve the distance relations, the two datasets were converted to the SWEREF99 coordinate system. ${ }^{35}$

\section{Categorisation of urban areas}

For analysis of the geographical distribution of public OHCAs and public AEDs in urban areas of Stockholm County we used the classification: land with human activity or non-agricultural, taken from the UA decision matrix. These urban areas were reclassified as either: (1) residential areas; (2) non-residential areas; or (3) other areas, based on their dominant land use and land cover. The definitions and descriptions of the UA subcategories are found in section 4.6. of the mapping guide for UA. ${ }^{28}$

UA and it's classifications do not account for population density, inhabitants or visitors over time in these areas. It is merely a classification of the area's predominant use. ${ }^{28}$

The residential area class was aggregated from six UA land cover subcategories defined as areas with dominant residential or inner-city areas with central business districts and residential use. Non-residential areas comprise artificial surfaces where industrial, commercial or leisure and recreational use are predominant.

Areas defined in UA as road and rail networks and as areas with a strong human influence but not containing specific information determining if the area is residential or non-residential (ie, construction sites, dump sites and land without current use) were removed from the UA layer, and public OHCA and AEDs in these locations were coded as the nearest neighbouring area. For example, an OHCA occurring on a road passing through a residential area was coded as having occurred in the surrounding area, and an OHCA occurring at a construction site within a non-residential area was consideredto occur in the surrounding or neighbouring area. The class 'other areas' was created from land with little or no human influence, in UA defined as agricultural, semi-natural areas, wetlands and forests. ${ }^{28}$ Areas of Stockholm County defined in UA as water were excluded from analysis of OHCA and AED locations. Figure 1 gives a closer description of the urban subcategories including map cut-outs for easier interpretation and shows the reclassification of residential and non-residential areas.

In the new residential and non-residential area categories, the subcategories from UA were kept but renamed for easier referral. The residential area subcategories were named $\mathrm{R}$ (for residential) and numbered R1 to R6 (figure 1). The numbering indicates a decreasing continuity of building density and soil sealing from R1 (the most dense urban area) to R5 (defined as a discontinuous urban area of very low density) and R6 (isolated structures) according to the UA decision matrix. ${ }^{28}$ The non-residential area subcategories were named NR (for non-) and numbered NR1 to NR4 (figure 1).

\section{GIS computation of public OHCA and AED relations}

To identify the locations of public OHCA incidence and AEDs, the respective coordinates were joined with the
UA layer using the spatial join tool in the GIS software QGIS 2.10. ${ }^{36}$ For comparison of Euclidean distance (ie, straight line distance between OHCA and the nearest AED), the function 'nearest neighbour' in QGIS 2.10 was used.

\section{Statistics}

Descriptive statistics were calculated in IBM SPSS 22.0 for Mac (IBM, Armonk, NewYork, USA). The Mann-Whitney U-test was used to test significance for continuous variables. p Values of correlation were calculated with Spearman's rank correlation coefficient and $\mathrm{p}$ values $<0.05$ were considered statistically significant.

\section{RESULTS}

Between 1 January 2012 and 31 December 2014 a total of 804 OHCAs occurred in public locations in Stockholm County and 1828 publicly available AEDs in the region were registered in SAEDREG by 31 December 2013.

The reclassified land use/land cover data comprises $643 \mathrm{~km}^{2}$ of residential areas, $311 \mathrm{~km}^{2}$ of non-residential areas and $5220 \mathrm{~km}^{2}$ of other areas (table 1). Further on in this section the relationship between public OHCAs and AEDs is presented for the new land use classes residential and non-residential areas. The results for other areas are presented solely in table 1 .

There were only small differences in the incidence of public OHCAs between the three urban areas in relation to daily or yearly temporal variation.

\section{Public OHCA incident locations}

In the new land use class defined as residential areas, $380(47.3 \%)$ of the public OHCAs occurred compared with $349(43.4 \%)$ in non-residential areas. The largest proportion of public OHCAs in the subcategories residential and non-residential areas was in R3 where 104 $(12.9 \%)$ occurred and in NR1 where 228 (28.4\%) occurred (table 1).

\section{Public AED locations}

Of the publicly available AEDs, 537 (29.4\%) were located in residential areas and $1258(68.8 \%)$ were located in non-residential areas. The largest proportion of all public AEDs in the subcategories of residential and non-residential areas was in R1 where $14.6 \%$ were located and in NR1 where $59 \%$ were located (table 1 ).

\section{Public OHCA incident locations and public AED locations}

In residential areas the highest proportion of public OHCAs $(27 \%, 104 / 380)$ occurred in R3 where the AED proportion was $11 \%(59 / 537)$. The highest proportion of AEDs in residential areas $(50 \%, 267 / 537)$ was found in R1 where 21\% (80/380) of the public OHCAs occurred. In non-residential areas the highest proportion of public OHCAs $(65 \%, 228 / 349)$ was in NR1 where the highest proportion of AEDs $(86 \%, 1079 / 1258)$ was also found (table 1). 
Residential areas

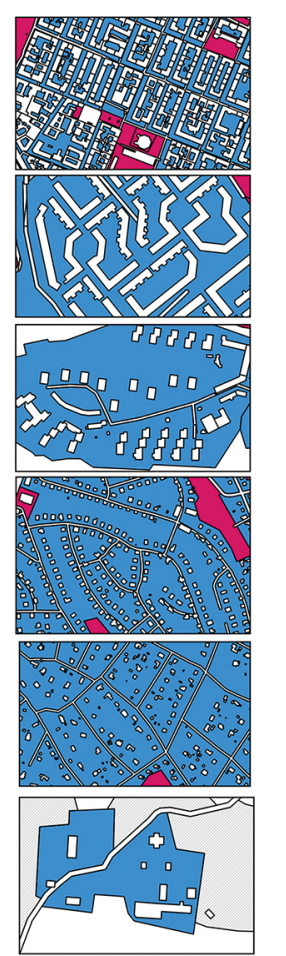

UA class 1.1.1 Continuous urban fabric.

Land Use: Predominant residential use. Downtown areas and city centres with residential use, in these particular cases blocks of houses, often high rise buildings.

Land Cover: Average degree of soil sealing $>80 \%$, vegetation and bare soil are exceptional.

UA class 1.1.2.1 Discontinuous urban fabric.

Land Use: Suburban and/or city centre areas with single family houses or highrise buildings.

Land Cover: Soil sealing degree $50 \%-80 \%$. Non-sealed areas may be planted areas, small parks, playgrounds or common green areas.

UA class 1.1.2.2 Discontinuous urban fabric.

Land Use: Residential area but the vegetated areas (gardens/lawns) is predominant. Single housings in suburban areas.

Land Cover: Soil sealing degree 30\%-50\%. Non-sealed areas are private gardens or common green areas and playgrounds.

UA class 1.123 Discontinuous urban fabric

Land Use: Residential area but vegetated areas (private gardens/lawns) is predominant. Single houses, farther apart. Suburban or semi-rural areas. Land Cover: Soil sealing degree $10 \%-30 \%$. Non-sealed areas are larger private gardens or common green areas.

UA class 1.1.2.4 Discontinuous urban fabric.

Land Use: Residential area but vegetated areas (private gardens/lawns) is predominant but not dedicated to forestry or agricultural. Single houses with large gardens in suburban/semi-rural areas.

Land Cover: Soil sealing degree $0 \%-10 \%$. Non-sealed areas are large private qardens.

UA class 1.1.3 Isolated structures.

Land Use: Rural areas, small individual farm houses and related buildings.

Land Cover: Buildings are not surrounded by any urban class but agricultural areas as fields or forests.

\section{Non-residential areas}

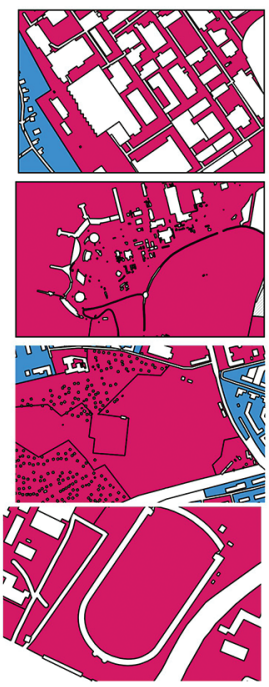

UA class 1.2.1 Industrial, commercial, public, military and private units Land Use: For example shopping malls and industrial compounds, high-rise office buildings, governmental buildings, schools and hospitals all with surrounding parking areas and garages. Land Cover: Artificial structures or artificial surfaces and associated areas as roads and vegetated areas.

UA classes 1.2.3+ 1.2.4 Port and Airport areas.

Land Use: Administrative area of inland harbours/seaports and airports. Land Cover: All port and airport installations including runways, docks, quays and other associated areas.

UA class 1.4.1 Green urban areas.

Land Use: Public green areas for recreational use as parks, gardens and zoos.

Land Cover: Artificial or non-artificial green areas and suburban natural areas that are managed as urban parks.

UA class 1.4.2 Sports and leisure facilities

Land Use: Sport and leisure facilities as golf courses, sports fields

racecourses, amusement parks, marinas and swimming pools.

Land Cover: Artificial areas made to suit the use of the facility.

Figure 1 Description of the Urban Atlas (UA) subcategories creating the residential and non-residential areas of Stockholm, Sweden including map cut-outs for visualisation. The text includes the original UA subcategory numbering as well as UA land use and land cover descriptions. R, residential area (R1-R6);NR, non-residential area (NR1-NR4); UA, Urban Atlas.

\section{Median distance from OHCA to AED}

The median distance from public OHCA to the nearest AED was significantly shorter in non-residential areas than in residential areas ( $188 \mathrm{~m}$ vs $288 \mathrm{~m}, \mathrm{p}<0.001)$. The IQR was $60.0-475.1 \mathrm{~m}$ for residential areas and 120.8$655.6 \mathrm{~m}$ for non-residential areas.

The two subcategories with the largest proportions of public OHCA (R3 in residential areas and NR1 in non-residential areas) had a median distance of $355 \mathrm{~m}$ and $141.6 \mathrm{~m}$, respectively, from the OHCA to the nearest AED. The shortest median distance from a public OHCA to the nearest AED and the only median distance below $100 \mathrm{~m}$ was found in subcategory R1 (table 1 ).

\section{DISCUSSION}

The main finding of this study is that, even though the incidence locations of public OHCA in Stockholm County were evenly distributed between areas defined by $\mathrm{UA}^{28}$ as residential and non-residential areas, more than two-thirds of the available AEDs were located in non-residential areas. 
Table 1 Locations of public out-of-hospital cardiac arrests (OHCAs) and automated external defibrillators (AEDs) in urban areas of Stockholm, Sweden and characteristics for distance from OHCA to AED, ambulance response time and 30-day survival per urban area

\begin{tabular}{|c|c|c|c|c|c|c|c|c|}
\hline & $\begin{array}{l}\text { Public } \\
\text { OHCA }\end{array}$ & $\begin{array}{l}\text { Public } \\
\text { available } \\
\text { AED }\end{array}$ & Area & $\mathrm{OHCA} / 100 \mathrm{~km}^{2}$ & AED $/ 100 \mathrm{~km}^{2}$ & $\begin{array}{l}\text { Distance } \\
\text { OHCA to } \\
\text { AED (median) }\end{array}$ & $\begin{array}{l}\text { Ambulance } \\
\text { response } \\
\text { time } \\
\text { (median) }\end{array}$ & $\begin{array}{l}\text { 30-day } \\
\text { survival }\end{array}$ \\
\hline & $\%(n)$ & $\%(n)$ & $\mathrm{km}^{2}$ & $n$ & $n$ & $\mathrm{~m}$ & $\min$ & $\%$ \\
\hline $\begin{array}{l}\text { Residential } \\
\text { areas }\end{array}$ & $47.3(380)$ & $29.4(537)$ & 643 & 7.4 & 83.5 & 288.4 & 11.0 & 17.8 \\
\hline $\begin{array}{l}\text { R1 (UA 1.1.1 } \\
\text { Continuous, } \\
\text { SL >80\%) }\end{array}$ & $10(80)$ & $14.6(267)$ & 6.6 & 151.5 & 4045.5 & 98.7 & 8.0 & NA \\
\hline $\begin{array}{l}\text { R2 (UA 1.1.2.1 } \\
\text { Discontinuous } \\
\text { Dense, SL } \\
\text { 50-80\%) }\end{array}$ & $6.7(54)$ & $4.8(88)$ & 16.8 & 39.9 & 523.8 & 186.3 & 10.0 & NA \\
\hline $\begin{array}{l}\text { R3 (UA 1.1.2.2 } \\
\text { Discontinuous } \\
\text { Medium } \\
\text { Density, SL } \\
\text { 30-50\%) }\end{array}$ & 12.9 (104) & $3.2(59)$ & 62.5 & 20.6 & 94.4 & 355 & 11.0 & NA \\
\hline $\begin{array}{l}\text { R4 (UA 1.1.2.3 } \\
\text { Discontinuous } \\
\text { Low Density, } \\
\text { SL 10-30\%) }\end{array}$ & $11.7(94)$ & $3.9(72)$ & 186.4 & 6.3 & 38.6 & 520.4 & 13.0 & NA \\
\hline $\begin{array}{l}\text { R5 (UA 1.1.2.4 } \\
\text { Discontinuous } \\
\text { Very Low } \\
\text { Density, } \\
\text { SL < } 10 \% \text { ) }\end{array}$ & $5.1(41)$ & $2.4(44)$ & 307.4 & 1.7 & 14.3 & 928.9 & 14.50 & NA \\
\hline $\begin{array}{l}\text { R6 (UA 1.1.3. } \\
\text { Isolated } \\
\text { Structures) }\end{array}$ & $0.9(7)$ & $0.4(7)$ & 63.7 & 1.4 & 11 & 1309.1 & 18.0 & NA \\
\hline $\begin{array}{l}\text { Non- } \\
\text { residential } \\
\text { areas }\end{array}$ & 43.4 (349) & $68.8(1258)$ & 310.9 & 14 & 404.6 & 187.6 & 11.0 & 24.1 \\
\hline $\begin{array}{l}\text { NR1 (UA 1.2.1 } \\
\text { Industrial, } \\
\text { commercial etc) }\end{array}$ & 28.4 (228) & 59 (1079) & 119.7 & 23.7 & 901.4 & 141.6 & 9.50 & NA \\
\hline $\begin{array}{l}\text { NR2 (UA 1.2.4 } \\
\text { Airports) }\end{array}$ & $2(16)$ & $1.9(35)$ & 12 & 16.7 & 291.7 & 139 & 16.50 & NA \\
\hline $\begin{array}{l}\text { NR3 (UA 1.4.1 } \\
\text { Green urban } \\
\text { areas) }\end{array}$ & $6.1(6.1)$ & $0.8(15)$ & 87.6 & 7 & 17.1 & 348.7 & 12.0 & NA \\
\hline $\begin{array}{l}\text { NR4 (UA 1.4.2 } \\
\text { Sports and } \\
\text { leisure facilities) }\end{array}$ & $7(56)$ & $7.1(129)$ & 91.6 & 7.6 & 140.8 & 417.7 & 11.0 & NA \\
\hline Other areas & $9.3(75)$ & $1.8(33)$ & 5291.7 & 0.2 & 0.6 & 1217.5 & 16.0 & 10.8 \\
\hline $\begin{array}{l}\text { O1 (UA 2 } \\
\text { Agricultural + } \\
\text { Semi-natural } \\
\text { areas }+ \\
\text { Wetlands) }\end{array}$ & $3.5(28)$ & $0.7(12)$ & 1331.9 & 0.3 & 0.9 & 1087.6 & 17.0 & NA \\
\hline $\begin{array}{l}\text { O2 (UA } 3 \\
\text { Forests) }\end{array}$ & $5.8(47)$ & $1.1(21)$ & 3959.8 & 0.1 & 0.5 & 1414.6 & 16.0 & NA \\
\hline
\end{tabular}




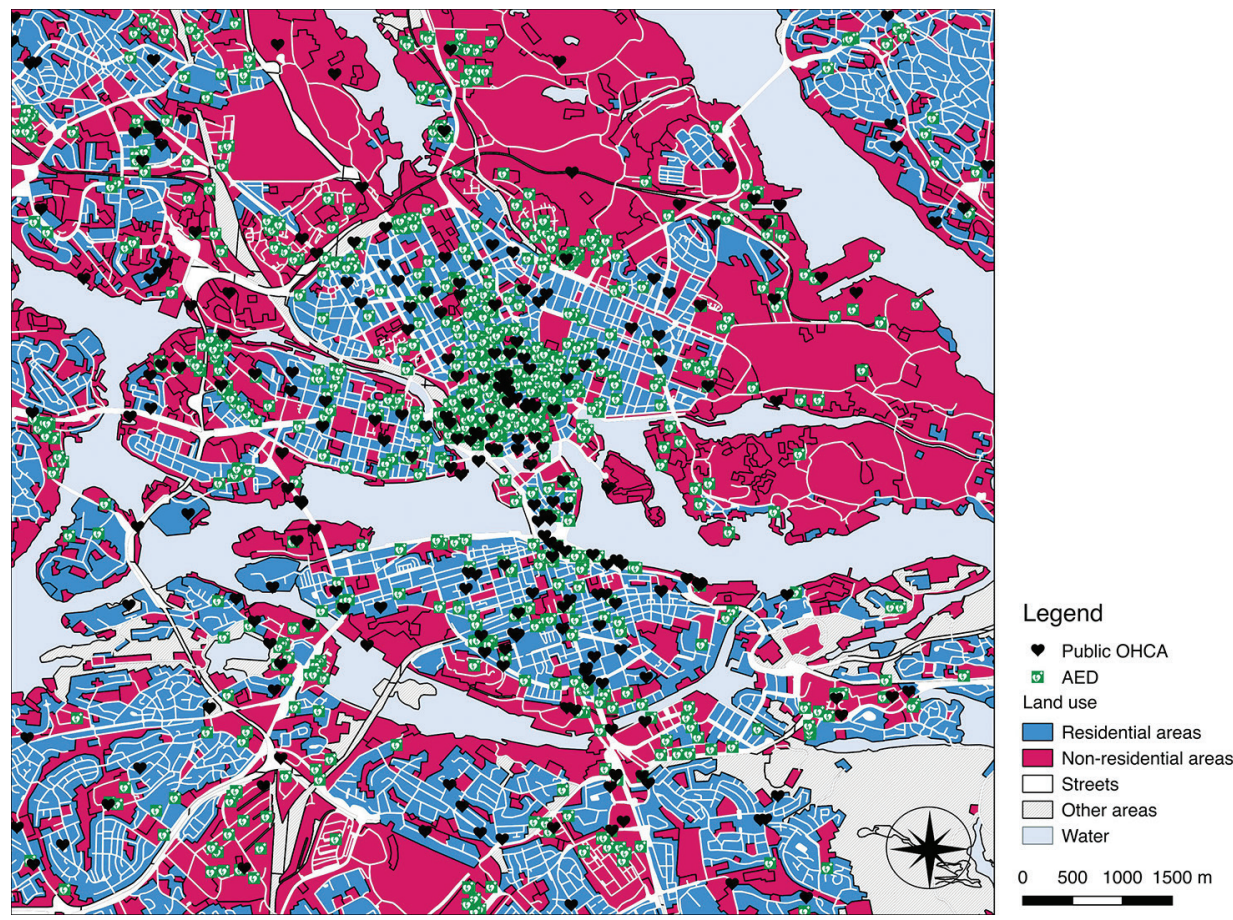

Figure 2 A map of the central and closest suburban areas of Stockholm, Sweden visualising the representation of residential and non-residential areas according to our reclassification of the Urban Atlas (UA) land cover classes and the distribution of public OHCA locations and AED locations. AED, automated external defibrillator; OHCA, out-of-hospital cardiac arrest.

Figure 2 depicts the locations of public AEDs and public OHCA incidences in the central and closest suburban areas of Stockholm city and figure 3 displays a close-up of an area where the mismatch between OHCA incidence locations and AED installations in residential and non-residential areas is clearly visible.

\section{OHCA incidence location}

According to the Utstein Resuscitation Registry templates, the specific location of an OHCA should be reported to aid communities to optimise resources. The Utstein template for reporting OHCA incident locations suggests

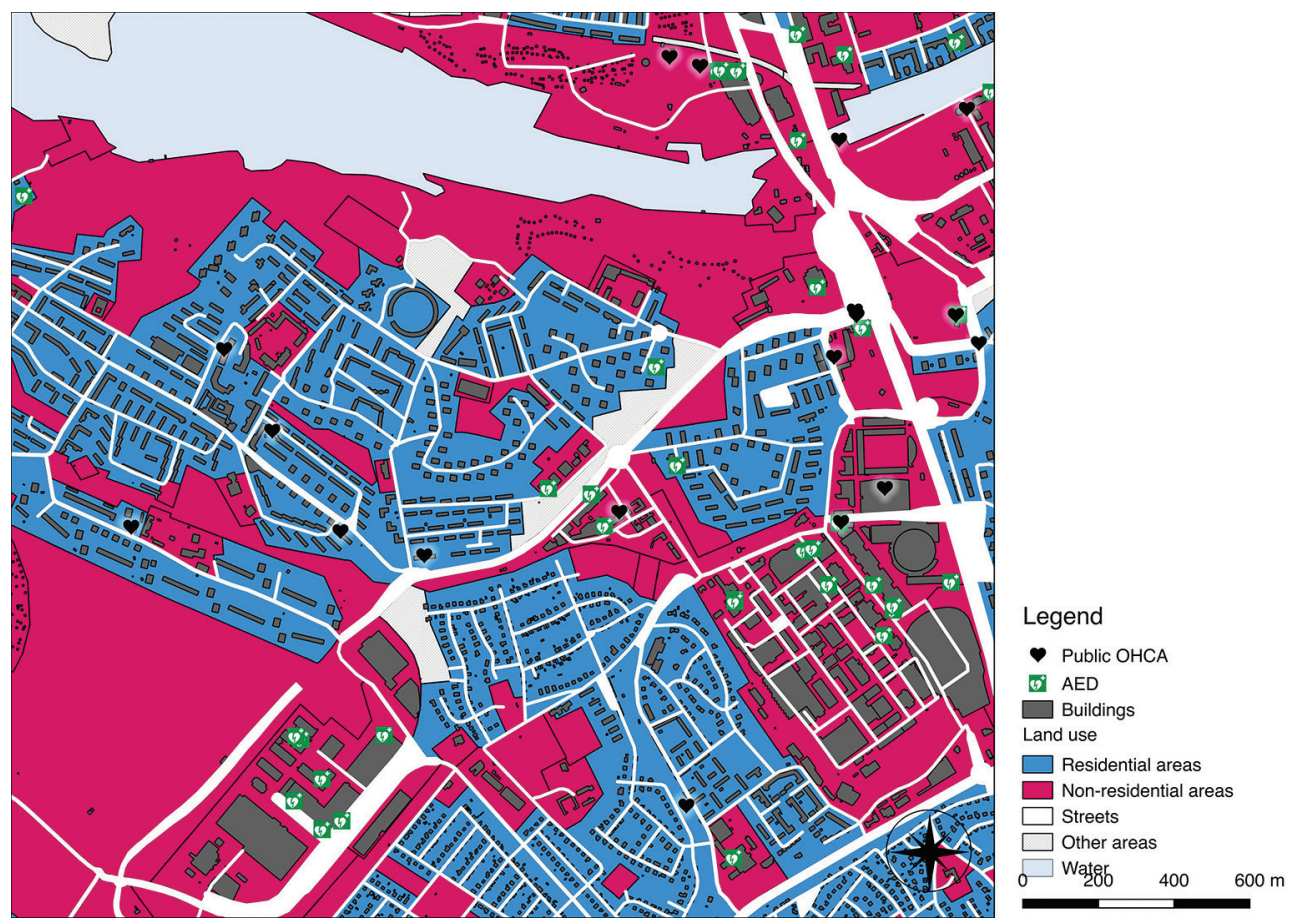

Figure 3 Close-up of an area just south-west of the central parts of Stockholm, Sweden. This visualises the mismatch in public OHCA incidence and AED locations between residential and non-residential areas. AED, automated external defibrillator; OHCA, out-of-hospital cardiac arrest. 
the following reporting options: home/residence; industrial/workplace; sports/recreation event; institution; other and unspecified/unknown/not recorded. ${ }^{37}$

Data on public OHCA incidence in the present study were acquired from the SRCR, an Utstein style cardiac arrest registry with a high level of inclusion and validity ${ }^{38}$ that uses a modified Utstein template for reporting the incidence location of OHCAs. ${ }^{25}$ In Sweden, 'street and square' is the most common reported location for OHCAs in public locations over the last 8 years, comprising $7.6 \%$ of 17756 reported OHCAs. ${ }^{25}$ Nonetheless, residential locations are still the most common location for OHCAs in Sweden ${ }^{25}$ and internationally. ${ }^{9} 39$

An OHCA reported as occurring in a street location could have dramatically different likelihood for AED use, depending on whether the street location is on the parking lot of a large shopping mall or on the kerb outside a suburban housing area-that is, in a non-residential or residential area according to the UA classification. The same may apply for bystander CPR rates in different locations based on numbers of visitors and accessibility, but this is not analysed in the present study.

A study from Japan reported that $9.5 \%$ of bystander-witnessed OHCAs occurred in public locations. A high rate of AED use was reported from railway stations (41.2\%) and sport facilities $(56.5 \%)$, although with low actual numbers of cases $(n=17$ and $n=23$, respectively). However, $562(68 \%)$ of the public OHCAs in the study reportedly occurred in locations defined as 'other' according to the Utstein template, and here the AED use was as low as $3.6 \% .^{9}$ It is reasonable to believe-but not further elaborated on-that these 'other' locations are very diversified.

We believe the data reporting options suggested by the Utstein template may somewhat limit the understanding of the low AED usage.

In the present study we have analysed all OHCAs in public locations, regardless of the location reported in SRCR. This method of including all public OHCAs regardless of locations allowed us to include and analyse OHCA cases in locations reported as 'unknown' or 'other', in contrast to the Japanese study, and this revealed an equal incidence of public OHCAs in residential or non-residential areas. This, in our opinion, more objective approach to analysing incidence locations of public OHCAs and AEDs based on area rather than the traditional more subjective use of locations reported by ambulance crews, could add valuable insights to this field of research. Figure 3 visualises an area of Stockholm where the mismatch between public OHCA incidence locations and AED installation sites is clearly visible.

It is, however, important to clarify that UA and the subcategory classifications used in this work do not reflect population density, inhabitants or number of visitors.

\section{AED location}

In the present study two-thirds of the AEDs were located in non-residential areas. A Canadian study reported similar findings when categorising public OHCA incident locations and AED installation sites as either in or outside the downtown area. The study reported that the downtown area had a greater AED coverage of public OHCAs than outside the downtown area (49\% vs $17 \%$ ), but at the same time $80 \%$ of the public OHCAs occurred outside the downtown area. ${ }^{17}$ This indicates a tendency for AED installations in commercial areas of the urban environment.

Current European Resuscitation Council guidelines suggest that AEDs should be placed in locations with many visitors and specifically point out public locations such as train and bus stations, airports, sport facilities, casinos and shopping malls. ${ }^{1}$ However, the guidelines also suggest that AEDs should be placed in densely populated areas but do not specify such locations or the appropriate level of density. ${ }^{1}$ In the present study we noted a higher public OHCA incidence in residential areas which, according to UA, consist of low and medium density housing areas, than in areas of a more dense character ${ }^{28}$ (table 1 and figure 1). This raises the question of how densely populated an area should be in order to be considered a target for AED installation.

With guidelines specifically pointing out locations for AED installation mainly present in areas in UA defined as non-residential areas, an unfavourable mismatch between AED locations and public OHCA incidence locations may be the result, as the present study suggests.

Previous work from the USA described a poor association between location of OHCAs and AED placements and stated that no AEDs were located in the most frequent locations for OHCAs. ${ }^{40}$ That study included OHCAs in patients' homes, which we believe may obscure the analysis of associations between OHCA and AED locations. Previous work concludes that public AED use is most effective in public settings ${ }^{10} 4142$ and not in peoples' homes. ${ }^{11}$ Systems that use mobile telephones to alert volunteer laypersons to reach OHCA victims in their home environment have been introduced. ${ }^{43-46}$ This may somewhat eliminate the effect of mismatch in AED installations shown in the present study.

Some caution should be observed when using UA for evaluating health outcomes since it was primarily developed as a tool for pan-European urban planning purposes. Our findings of relationships between public OHCA and AED locations need to be verified in or between other cities, regions or countries. With the UA datasets freely downloadable for most major cities/urban zones of the European Union, a reproduction of our study is possible if AED and OHCA registries with geocoded datasets are available.

Based on the findings from the present study, we aim to identify possible locations for AED installations more evenly distributed between residential and non-residential areas of Stockholm County.

\section{Distance from OHCA to AED}

We noticed a significantly lower median distance between public OHCAs and AEDs in non-residential areas 
compared with residential areas. A possible explanation is that area size and AED enumeration is the key to a favourable distance or coverage (table 1). A distance of 100 metres to the nearest AED is assumed an 'upper limit' for defibrillation within the early critical 3-5 min. ${ }^{151618} \mathrm{~A}$ median distance of less than 100 metres only appeared in the smallest $\left(6.6 \mathrm{~km}^{2}\right)$ residential area subcategory, $\mathrm{R} 1$. According to UA reference publications, this subcategory includes downtown areas and city centres. ${ }^{28}$ In this area the highest $\mathrm{AED} / 100 \mathrm{~km}^{2}$ value is identified, due to its small size but high rate of AEDs (table 1).

The previously mentioned Canadian study showed a $60 \%$ lower median distance between public OHCAs and AEDs in downtown areas. The authors reflect on the shorter median distance being a result of higher numbers of AEDs located in a smaller area. ${ }^{17}$ This raises the question whether the AED $/ 100 \mathrm{~km}^{2}$ ratio may be as valid as the suggested 100 metre distance, widely adopted, but not verified by randomised trials.

\section{CONCLUSION}

Our results show that the majority of public OHCAs in Stockholm County occur in areas classified in UA as residential areas, where AED accessibility is limited. Our findings indicate that residential areas need to be considered priority targets for AED installation and that looking at area rather than location, using geodata tools such as UA and GIS, can contribute to identifying these areas. We also believe that international guidelines need to take geographical location into account when suggesting locations for AED installations.

Correction notice This paper has been amended since it was published Online First. Owing to a scripting error, some of the publisher names in the references were replaced with 'BMJ Publishing Group'. This only affected the full text version, not the PDF. We have since corrected these errors and the correct publishers have been inserted into the references.

Acknowledgements We wish to thank Mona Bergström-Ling at the national dispatch organisation SOS Alarm AB, Stockholm, for invaluable help in the retrieving of GPS coordinates for the OHCA cases. We wish to give a virtual 'high-five' to Marvin McCutchan at KTH for the great work with the visualisation of the figures.

Contributors Study concept and design: DF, MJ, JH, YB, AC, LS. Acquisition of data: DF, MJ, JH. Analysis and interpretation of data: DF, MJ, JH. Drafting of the manuscript: DF, MJ, AC, LS. Critical revision of the manuscript for important intellectual content: DF, MJ, LS, AC, YB, TD, JH, MR, PN. Statistical analysis: DF, MJ, JH. Obtained funding: LS. Study supervision: AC, LS, YB.

Funding This work was supported by a centre support grant from the Laerdal Foundation and by unrestricted grants from Hjärt-lungfonden (the Swedish Heart and Lung Foundation) and Stockholm County Council. These funders had no role in study design, data collection and analysis, decision to publish or preparation of the manuscript.

Competing interests None declared.

Ethics approval The regional ethics committee in Stockholm County approved the study, (2014/1134-31/2).

Provenance and peer review Not commissioned; externally peer reviewed.

Data sharing statement Availability of data and material: The OHCA and AED data supporting the findings of this study are available upon reasonable request, but restrictions apply to the availability and sharing of these data, which were used by the authors under license for the current study. Data are available from the following sources: Swedish AED data can be obtained by special permission from the owner of the SAEDREG, the Swedish Resuscitation Council (info@hlr.nu). Data on OHCA incident locations from SRCR can be obtained by special permission from Registercentrum Västra Götaland, Sweden. Urban Atlas shapefiles are freely downloadable from the European Environment Agency .

Open Access This is an Open Access article distributed in accordance with the Creative Commons Attribution Non Commercial (CC BY-NC 4.0) license, which permits others to distribute, remix, adapt, build upon this work non-commercially, and license their derivative works on different terms, provided the original work is properly cited and the use is non-commercial. See: http://creativecommons.org/ licenses/by-nc/4.0/

(c) Article author(s) (or their employer(s) unless otherwise stated in the text of the article) 2017. All rights reserved. No commercial use is permitted unless otherwise expressly granted.

\section{REFERENCES}

1. Perkins GD, Handley AJ, Koster RW, et al. Adult basic life support and automated external defibrillation section Collaborators. European Resuscitation Council guidelines for resuscitation 2015: Section 2. Adult basic life support and automated external defibrillation. Resuscitation 2015;95:81-99.

2. Gräsner JT, Bossaert L. Epidemiology and management of cardiac arrest: what registries are revealing. Best Pract Res Clin Anaesthesiol 2013;27:293-306.

3. Berdowski J, Berg RA, Tijssen JG, et al. Global incidences of outof-hospital cardiac arrest and survival rates: systematic review of 67 prospective studies. Resuscitation 2010;81:1479-87.

4. Valenzuela TD, Roe DJ, Nichol G, et al. Outcomes of rapid defibrillation by security officers after cardiac arrest in casinos. $N$ Engl J Med 2000;343:1206-9.

5. Ringh M, Jonsson M, Nordberg P, et al. Survival after public access defibrillation in Stockholm, Sweden: A striking success. Resuscitation 2015;91:1-7.

6. Kitamura T, Iwami T, Kawamura T, et al. Nationwide public-access defibrillation in Japan. N Engl J Med 2010;362:994-1004.

7. Agerskov M, Nielsen AM, Hansen CM, et al. Public access defibrillation: great benefit and potential but infrequently used. Resuscitation 2015;96:53-8.

8. Deakin CD, Shewry E, Gray HH. Public access defibrillation remains out of reach for most victims of out-of-hospital sudden cardiac arrest. Heart 2014;100:619-23.

9. Murakami Y, Iwami T, Kitamura T, et al. Outcomes of out-of-hospital cardiac arrest by public location in the public-access defibrillation era. J Am Heart Assoc2014;3:e000533.

10. Engdahl J, Herlitz J. Localization of out-of-hospital cardiac arrest in Goteborg 1994-2002 and implications for public access defibrillation. Resuscitation 2005;64:171-5.

11. Bardy GH, Lee KL, Mark DB, et al. Home use of automated external defibrillators for sudden cardiac arrest. $N$ Engl J Med 2008;358:1793-804.

12. Hansen $\mathrm{CM}$, Wissenberg M, Weeke $\mathrm{P}$, et al. Automated external defibrillators inaccessible to more than half of nearby cardiac arrests in public locations during evening, nighttime, and weekends. Circulation 2013;128:2224-31.

13. Schober P, van Dehn FB, Bierens JJ, et al. Public access defibrillation: time to access the public. Ann Emerg Med 2011;58:240-7.

14. Hansen CM, Lippert FK, Wissenberg M, et al. Temporal trends in coverage of historical cardiac arrests using a volunteer-based network of automated external defibrillators accessible to laypersons and emergency dispatch centers. Circulation 2014;130:1859-67.

15. Aufderheide T, Hazinski MF, Nichol G, et al. Community lay rescuer automated external defibrillation programs: key state legislative components and implementation strategies: a summary of a decade of experience for healthcare providers, policymakers, legislators, employers, and community leaders from the American Heart Association Emergency Cardiovascular Care Committee, Council on Clinical Cardiology, and Office of State Advocacy. Circulation 2006;113:1260-70.

16. Huang CY, Wen TH. Optimal installation locations for automated external defibrillators in Taipei 7-Eleven stores: using GIS and a genetic algorithm with a new stirring operator. Comput Math Methods Med 2014;2014:1-12.

17. Chan TC, Li H, Lebovic G, et al. Identifying locations for public access defibrillators using mathematical optimization. Circulation 2013;127:1801-9. 
18. Folke F, Lippert FK, Nielsen SL, et al. Location of cardiac arrest in a city center: strategic placement of automated external defibrillators in public locations. Circulation2009;120:510-17.

19. Gratton M, Lindholm DJ, Campbell JP. Public-access defibrillation: where do we place the AEDs?Prehosp Emerg Care 1999;3:303-5.

20 . Land use in Sweden 2010 (updated 2013-11-26. Land use in Sweden 2010). http://www.scb.se/en_/Finding-statistics/Statisticsby-subject-area/Environment/Land-use/Land-use-in-Sweden/ Aktuell-Pong/12857/Land-use-in-Sweden/ (accessed 10 Aug 2016).

21. Statistics SwedenPopulation in the country, counties and municipalities on 31/12/2015 and population change in 2015 Statistics Sweden; 2015 (updated 2016-02-22. 2015 Census Statistics of Sweden). http://www.scb.se/en_/Finding-statistics/ Statistics-by-subject-area/Population/Population-composition/ Population-statistics/Aktuell-Pong/25795/Yearly-statistics-Municipalities-Counties-and-the-whole-country/399347/ (accessed 10 August 2016).

22. Söderström PS, Ristimäki MH. Urban form in the Helsinki and Stockholm City regions development of pedestrian, public transport and car zones: Finnish Environment Institute, 2015.

23. Nordberg P, Jonsson M, Forsberg S, et al. The survival benefit of dual dispatch of EMS and fire-fighters in out-of-hospital cardiac arrest may differ depending on population density--a prospective cohort study. Resuscitation 2015;90:143-9.

24. Hollenberg J, Riva G, Bohm K, et al. Dual dispatch early defibrillation in out-of-hospital cardiac arrest: the SALSA-pilot. Eur Heart $J$ 2009;30:1781-9.

25. Herlitz J. Swedish register for Cardiopulmonary Resuscitation. Annual report 2015 (in Swedish) Swedish Resuscitation Council, 2015. http://www.hlr.nu/wp-content/uploads/Svenska-HLR-radetHLR-registret-arsrapport-2015-1.pdf (accessed 4 Apr 2016).

26. Perkins GD, Jacobsl G, Nadkarni VM, et al. Cardiac arrest and Cardiopulmonary Resuscitation Outcome Reports: update of the Utstein Resuscitation Registry Templates for Out-of-Hospital Cardiac Arrest: a statement for healthcare professionals from a taskforce of the International Liaison Committee on Resuscitation (American Heart Association, European Resuscitation Council, Australian and New Zealand Council on Resuscitation, Heart and Stroke Foundation of Canada, InterAmerican Heart Foundation, Resuscitation Council of Southern Africa, Resuscitation Council of Asia); and the American Heart Association Emergency Cardiovascular Care Committee and the Council on Cardiopulmonary, Critical Care, Perioperative and Resuscitation. Circulation 2015;132.

27. Jacobs I, Nadkarni V, Bahr J, et al. Cardiac arrest and cardiopulmonary resuscitation outcome reports: update and simplification of the Utstein templates for resuscitation registries. A statement for healthcare professionals from a task force of the International Liaison Committee on Resuscitation (American Heart Association, European Resuscitation Council, Australian Resuscitation Council, New Zealand Resuscitation Council, Heart and Stroke Foundation of Canada, InterAmerican Heart Foundation, Resuscitation Council of Southern Africa). Resuscitation 2004;63:233-49.

28. European Union. Mapping Guide for a European urban atlas. 2011http://www.eea.europa.eu/data-and-maps/data/urban-atlas (accessed 3 November 2016).

29. European Environment Agency. Urban atlas - dataset download: European Union shapefiles of urban atlas in. zip format. 2016http:// www.eea.europa.eu/data-and-maps/data/urban-atlas (accessed 25 February 2016).

30. Kabisch N, Strohbach M, Haase D, et al. Urban green space availability in European cities. Ecological Indicators 2016;70:586-96

31. Jokar Arsanjani J, Vaz E. An assessment of a collaborative mapping approach for exploring land use patterns for several European metropolises. Int J Appl Earth Observation and GeoinformationPart B 2015;35:329-37

32. MonteroE, Van WolvelaerJ, GarzónA. The European Urban Atlas. In: Manakosl, BraunM, eds. Land Use and Land Cover Mapping in Europe: Practices \& Trends. The Netherlands: Dordrecht, 2014:115-24.

33. Lantmäteriet. Two-dimensional systems RT90 2016. https://www. lantmateriet.se/en/Maps-and-geographic-information/GPS-andgeodetic-surveys/Reference-systems/Two-dimensional-systems/ RT-90/ (accessed 15 August 2016).

34. Lantmäteriet. Three-dimensional systems WGS84 2016. http://www. lantmateriet.se/en/Maps-and-geographic-information/GPS-andgeodetic-surveys/Reference-systems/Three-dimensional-systems/ WGS-84/ (accessed 15 August 2016).

35. Lantmäteriet. Two-dimensional systems SWEREF99 2016. https:// www.lantmateriet.se/en/Maps-and-geographic-information/ GPS-and-geodetic-surveys/Reference-systems/Two-dimensionalsystems/SWEREF-99-projections/ (accessed 15 August 2016).

36. QGIS Geographic Information System [program]. 2.10 version: open Source Geospatial Foundation Project. 2016.

37. PerkinsGD, JacobsiG, NadkarniVM, et al. Cardiac arrest and cardiopulmonary resuscitation outcome reports: update of the Utstein Resuscitation Registry templates for out-of-hospital cardiac arrest. Resuscitation 2014;96:328-40.

38. Strömsöe A, Svensson L, Axelsson ÅB, et al. Validity of reported data in the Swedish Cardiac Arrest Register in selected parts in Sweden. Resuscitation 2013;84:952-6.

39. Weisfeldt ML, Sitlani CM, Ornato JP, et al. Survival after application of automatic external defibrillators before arrival of the emergency medical system: evaluation in the resuscitation outcomes consortium population of 21 million. J Am Coll Cardiol 2010;55:1713-20.

40. Levy MJ, Seaman KG, Millin MG, et al. A poor association between out-of-hospital cardiac arrest location and public automated external defibrillator placement. Prehosp Disaster Med 2013;28:342-7.

41. Winkle RA. The effectiveness and cost effectiveness of public-access defibrillation. Clin Cardiol 2010;33:396-9.

42. Hallstrom AP, Ornato JP, Weisfeldt M, et al. Public-access defibrillation and survival after out-of-hospital cardiac arrest. N Engl J Med 2004;351:637-46.

43. Ringh M, Fredman D, Nordberg P, et al. Mobile phone technology identifies and recruits trained citizens to perform CPR on outof-hospital cardiac arrest victims prior to ambulance arrival. Resuscitation 2011;82:1514-8.

44. Ringh M, Rosenqvist M, Hollenberg J, et al. Mobile-phone dispatch of laypersons for CPR in out-of-hospital cardiac arrest. N Engl $J$ Med 2015;372:2316-25.

45. Brooks SC, Simmons G, Worthington $\mathrm{H}$, et al. The PulsePoint Respond mobile device application to crowdsource basic life support for patients with out-of-hospital cardiac arrest: challenges for optimal implementation. Resuscitation 2016;98:20-6.

46. Zijlstra JA, Stieglis R, Riedijk F, et al. Local lay rescuers with AEDs, alerted by text messages, contribute to early defibrillation in a Dutch out-of-hospital cardiac arrest dispatch system. Resuscitation 2014;85:1444-9. 